\title{
A Study on Weekly Iron and Folic Acid Supplementation (WIFS) Programme in a School at Rural Area of West Bengal, India
}

\author{
Dr. Arkaprabha Sau \\ Junior Resident, Department Of Community Medicine, R. G. Kar Medical College And Hospital, Kolkata, India
}

\begin{abstract}
The Govt. of India, launched weekly IFA tablet Supplementation (WIFS) Programme on 2013 under $R M N C H+A$ approach to cope up with the problem of iron deficiency anaemia among adolescent boys and girls. Aims: To assess the compliance to IFA tablets among the students, to find out the causes of non-compliance among them and to assess the involvement of teachers into the programme.

Study Settings: Nachinda J. K. High School, Purba Medinipur, West Bengal.

Materials and Methods: An observational-descriptive study was carried out among 285 sample students of class VI to XII from 20th September to 20th October, 2015. Selected students and all the teachers were interviewed using predesigned schedule. Statistical analysis is done by Epi InfoTM 7.

Results and Discussions: Out of 285 students $67.7 \%$ were "Compliant" to IFA tablet. Two most important causes of noncompliance were "Fear of Harm/Unpleasant side effects" and "Past experience of side effects". There is statistically significant association between the Noncompliance with "Fear of Harm/Unpleasant side effects" (P<0.05).Only $80 \%$ of the teachers had taken IFA tablet before distribution and $83 \%$ ensure not to be consumed the tablet before meal.

Conclusions: Fears of Harm/Unpleasant side effects have significant association with non-compliance. Proper IEC and BCC may help to increase the compliance.
\end{abstract}

Keywords: Adolescents, Anaemia, IFA Tablet, WIFS

\section{Introduction}

Adolescents according to World Health Organization (WHO) are of age between 10-19 years. ${ }^{1}$ Data show that the number of adolescents are 1.2 billion worldwide ${ }^{2}$ and in India 243 million. ${ }^{3}$ During adolescence, both in boys and girls, second growth spurt of life $^{4}$ is seen, which significantly increases nutritional requirements, especially for iron. Anaemia, due to nutritional deficiency disorder, is an important public health problem among adolescent in our country, primarily occurs due to iron deficiency. ${ }^{5,6}$ According to National Family Health Survey (NFHS)-3, more than 55 percent of both adolescent boys and girls are anaemic. ${ }^{7}$ Adolescent girls in particular are more vulnerable to anaemia due to duel effect of rapid growth of the body and loss of blood during menstruation. In India, the highest prevalence of anaemia is reported between the ages 1213 years, ${ }^{8}$ which also coincides with the average age of menarche. During adolescence, iron deficiency anaemia can result in impaired physical, mental, cognitive development, reduced work performance and lower concentration on daily tasks. ${ }^{9}$ Regular consumption of iron-folic acid (IFA) supplements along with a diet rich in micronutrients is essential for the prevention of the disease. The Ministry of Health and Family Welfare (MOHFW), Govt. of India, has launched the Weekly Iron and Folic Acid Supplementation (WIFS) programme ${ }^{10}$ on 2013 popularly known as "Solid Bano India-With just one Blue pill a week" under RMNCH+A (Reproductive, Maternal, Newborn, Child and Adolescent Health) approach in National Health Mission (NHM) to cope up with the problems of high incidence and prevalence of iron deficiency anaemia amongst adolescent. WIFS provides 'continuum of care' ${ }^{12}$ to ensure equal importance on various life stages. WIFS is evidence based programmatic response to the existing problemthrough supervised weekly ingestion of IFA tablet supplementation and helminthic control by biannual Albendazole tablet. ${ }^{13}$ In India it was found that $33 \%$ of adolescents had a history of worm infestation. Worm Infestation interfere with food intake, absorption, and storage, which contribute to anaemia. ${ }^{14}$ The long term goal of this programme is to break the intergenerational cycle of anaemia. The programme implemented across the country both in rural and urban areas. The objective of this WIFS programme is to reduce the prevalence and severity of iron deficiency anaemia in adolescent population in the country. ${ }^{10}$ The target groups are government or government aided school going adolescent girls and boys in 6th to 12th class and out of school adolescent girls. Out of school adolescent girls will be provided IFA tablets through AWW (Angan Wari Worker) / Auxiliary Nurse Midwives (ANM) under Rajiv Gandhi Scheme For Empowerment of Adolescent Girls (RGSEAG) popularly known as "SABALA". ${ }^{15}$ The strategies for intervention are administration of supervised weekly IFA tablet containing 100mg of elemental iron and $500 \mathrm{mcg}$ of Folic acid using a fixed day approach i.e. on Monday, screening of target groups for moderate / severe anaemia and referring them to an appropriate health facility, biannual de-worming with albendazole $(400 \mathrm{mg})$ tablet, and health education for improving dietary intake and prevention of intestinal worm 
infestation. ${ }^{10,16}$ Convergence of MOHFW, with other key stakeholder ministries like the Ministry of Women and Child Development and Ministry of Human Resource Development is an integral part of implantation plan of the WIFS programme. Currently the programme has been implemented in all States / UTs and covers 11.2 crore beneficiaries including 8.4 crore in-school and 2.8 crore out of school adolescents. ${ }^{10}$ Keeping all these words in mind an attempt has been made by this study to know the current status of WIFS programme in a school at rural area of West Bengal with following objectives-to assess the compliance of WIFS programme among the students, to find out the causes of non-compliance to WIFS programme among them and to assess the involvement of teachers into the programme.

\section{Materials And Methods}

1. Study Setting: Nachinda J. K. High School (H.S), Nachinda, Marisda, Purba Medinipur, PIN-721444 is a higher secondary school at Purba Medinipur District of West Bengal in India.

2. Study Population: The study population composed of students from class VI to XII of academic year 2015-16 and all the teachers of that school.

3. Study Period: From $20^{\text {th }}$ September 2015 to $20^{\text {th }}$ October 2015 .

4. Study Design: Observational Descriptive study with Cross Sectional Design.

5. Sample Size and Sampling: There was total 1005 number of student within class VI to XII in the academic year 2015-16 at that school. Considering the compliance of adolescents to IFA tablets as $65 \%$ in west Bengal $^{17}$, alpha $(\alpha) 0.05$, and margin of error of $5 \%$, the sample size was 259 , calculated by using the Epi InfoTM7 software. Considering $10 \%$ non-response rate, the final sample size was 285 . Number of students from each class was determined by Probability Proportional to Size (PPS) and students from each class were selected randomly using Random Number table.

6. Data Collection: Students were interviewed, using predesigned and pretested schedule, after taking proper consent from their guardians. Along with this, all the teachers were also interviewed, using another predesigned and pretested schedule, after taking proper consent.

7. Data Analysis: Analysis was done using EpiInfoTM 7 software (version7.1.5). Appropriate statistical test like Chi square test was done whenever necessary.

\section{Result And Discussion}

After statistical analysis, the results can be summarized and discussed as follows. There were 167 (59\%) boys and $118(41 \%)$ girls among the sample population of 285 students. Among them, 39.3\% boys and $28.4 \%$ girls i.e. total $67.7 \%$ students are "Compliant" to IFA tablet consumption. According to the WIFS programme, those who take less than 4 tablets in a month are considered to be "Non-Compliant". "Among the students, $19.7 \%$ boys and $12.6 \%$ girls i.e. total $32.3 \%$ students are "Non-Compliant" to IFA tablet consumption. There is no statistically significant difference in Compliance between boys and girls $(\mathrm{P}>0.05, \alpha=5 \%, \mathrm{Df}=1)$ (Table-1). Causes of Non-Compliances (Fig-1)were - Didn't know the effect of the medicine (5\%), Taking "Vitamin" tablet/capsule regularly at home (8\%), Doubt in the quality of the medicine (9\%), Didn't consume Mid-Day Meal ${ }^{18}$ at school (10\%), Past experience of side effects $(16 \%)$ and Fear of Harm / Unpleasant side effects (52\%). There was no statistically significant difference in the causes of Non Compliance between boys and girls $(\mathrm{P}>0.05, \alpha=5 \%, \mathrm{Df}=1)$ (Table-2). Chi-Square test shows that there was statistically significant associationbetween Non-Compliance to IFA tablet only with "Fear of Harm/Unpleasant side effects". (P<0.05, $\alpha=5 \%$, Df $=1$ ) (Table-3). "Fear of Harm/Unpleasant side effects" perceived by the students were (Fig-2) -Liver Damage (6\%), Hair Fall (17\%), Vertigo (19\%), Obesity (21\%), Vomiting (28\%), and non-Specific (9\%). 96\% Students had consumed Albendazole $(400 \mathrm{mg})$ tablet within last 6 months. Though all the teachers were aware about the ongoing WIFS programme, only $80 \%$ and $40 \%$ of them correctly knew the composition of the IFA tablet and named of the tablet for deworming respectively. $80 \%$ of the teachers used to take one IFA tablet before giving the tablet to the students and $83 \%$ of them ensured not to be consumed the IFA tablet before meal. Only $28 \%$ of the teachers encourage the students to take food rich in vitamin-c like lemon, amla, orange etc and only $18 \%$ of them discourage the students to drink tea or coffee within an hour of consuming main meals and IFA tablet. 


\section{Figures And Tables}

Table-1: $2 \times 2$ contingency table for significance testing between Sex and Compliance among students $(n=285)$.

\begin{tabular}{|l|l|l|l|l|}
\hline Compliance to IFA Tablet & Compliant & Non-Compliant & Total & \multirow{2}{*}{ P Value } \\
\cline { 1 - 4 } Boys & 112 & 55 & 167 & \multirow{2}{*}{$\mathbf{0 . 8 8}$} \\
\hline Girls & 81 & 37 & 118 & \\
\hline Total & 193 & 92 & 285 & \\
\hline
\end{tabular}

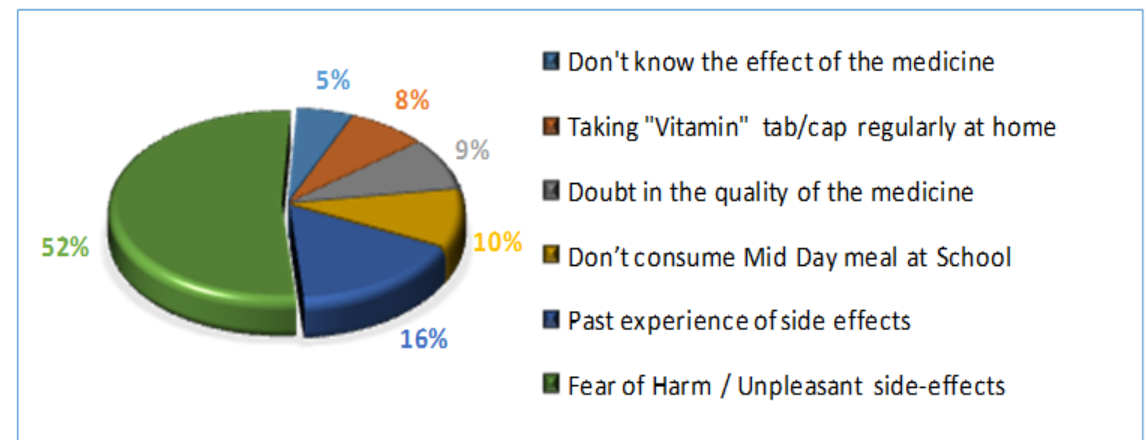

Fig-1: Pie diagram showing different causes of Non Compliance among the students $(n=285)$.

Table-2: Distribution of Causes of Non Compliance according to Sex ( $\mathrm{n}=92)$

\begin{tabular}{|l|l|l|l|}
\hline Causes of Non-Compliance & Boys & Girls & \multirow{2}{*}{ P Value } \\
\hline Don't know the effect of the medicine & 3 & 2 & \\
\hline Taking "Vitamin" tab/cap regularly at home & 5 & 4 & \\
\cline { 1 - 3 } Doubt in the quality of the medicine & 6 & 2 & \multirow{3}{*}{$>0.05$} \\
\hline Don't consume Mid-Day meal at School & 4 & 3 & \\
\cline { 1 - 3 } Past experience of side effects & 7 & 8 & \\
\cline { 1 - 3 } Fear of Harm / Unpleasant side effects & 30 & 18 & \\
\cline { 1 - 3 } Total & 55 & 37 & \\
\hline
\end{tabular}

Table-3: Association of Non - Compliance to IFA tablet and Fear of Harm / Unpleasant side effects $(\mathrm{n}=285)$.

\begin{tabular}{|c|c|c|c|c|c|}
\hline \multirow{2}{*}{\multicolumn{2}{|c|}{ Compliance to IFA Tablet }} & \multicolumn{2}{|c|}{ Compliant } & \multirow[t]{2}{*}{ Total } & \multirow[t]{2}{*}{ P value } \\
\hline & & No & Yes & & \\
\hline \multirow[t]{2}{*}{ Fear of Harm / Unpleasant side effect. } & Yes & 48 & 32 & 80 & \multirow{3}{*}{0.000} \\
\hline & No & 44 & 161 & 205 & \\
\hline Total & & 92 & 193 & 285 & \\
\hline
\end{tabular}

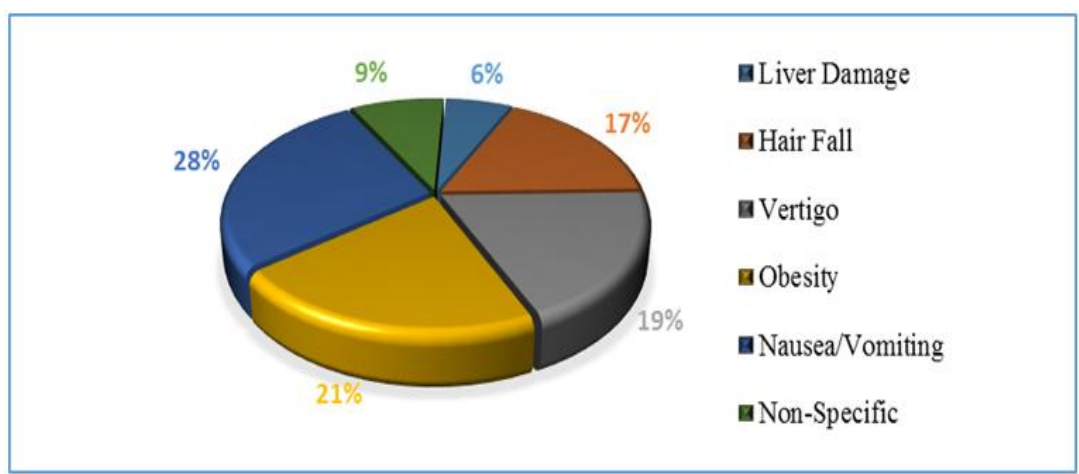

Fig-2: Distribution of different of Fear of Harm/Unpleasant side effects among the students $(\mathrm{n}=80)$

\section{Conclusion}

Certain level has been achieved in WIFS programme in terms of compliance to IFA and Albendazole tablet consumption but there is a huge scope of improvement. Fears of Harm/Unpleasant side effects have significant association with non-compliance to IFA tablet. Proper IEC (Information Education and Communication) and Behavioral Change Communication (BCC) to eliminate the fear of harm/unpleasant side effects will help to increase the compliance. Teachers may play an important role in this matter.

\section{Acknowledgements}

I am thankful to the headmaster, teachers, students and their parents for their kind and unconditional support. I am also thankful to my teachers for proper guidance. Special thanks to Dr. Sourav Kundu, Junior Resident, Dept. of Community Medicine, R. G. Kar Medical College, Kolkata for his valuable opinion. 


\section{References}

[1]. UNICEF. The State of the World's Children 2011-Executive Summary: Adolescence an age of opportunity: Unicef; 2011

[2]. Kotwal N, Khan N, Kaul S. A review of the effectiveness of the interventions on adolescent reproductive health in developing countries. IJSRP. 2014;4:1-4

[3]. Regmi K, Viji Prasad C, Jacob V. Research article a descriptive study to assess the knowledge of parents regarding suicidal behavior among adolescents in a selected community area at mangalore. International Journal of Recent Scientific Research. 2014;5(11):2085.

[4]. Gluckman PD, Hanson MA. Evolution, Development and timing of puberty. Trends in Endocrinology \& Metabolism.2006; 17 (1): 12 .

[5]. Kalaivani K. Prevalence \& consequences of anaemia in pregnancy. Indian J Med Res. 2009;130(5):627-33.

[6]. Lynch SR. The impact of iron fortification on nutritional anemia. Best practice \& research clinical hematology 2005; 18 (2): $333-$ 46

[7]. IIPS. India National Family Health Survey (NFHS-3), 2005-06: International Institute for Population Sciences; 2007.

[8]. Mathers C, Fat DM, Boerma JT. The global burden of disease: 2004 update: World Health Organization; 2008.

[9]. Walker SP, Wachs TD, Gardner JM, Lozoff B, Wasserman GA, Pollitt E, et al. Child development: risk factors for adverse outcomes in developing countries. The lancet.2007;369(9556):145-57.

[10]. NHM Components: National Health Mission; [Internet] 2013 [cited 2015 Nov 11]. Available from: http://nrhm.gov.in / nrhmcomponents / rmnch-a / adolescent-health-risk / weekly-iron folic-acid-supplementation/wifs/ background .html

[11]. Weekly Iron and Folic Acid Supplementation: National Health Mission; [Internet] 2013 [cited 2015 Nov 11]. Available from:http://nrhm.gov.in/nrhmcomponnets/reproductive-child-health/adolescent-health / wifs.html.

[12]. Reproductive, Maternal, Newborn, Child and Adolescent Health: National Health Mission; [Internet] 2013 [cited 2015 Nov 11] Available from:http://nrhm.gov.in / nrhm-components /rmnch-a.html.

[13]. World Health Organization. Weekly iron and folic acid supplementation programmes for women of reproductive age: an analysis of best programme practices. 2011

[14]. Rawat CMS. An epidemiological study of anaemia in adolescent girls in the rural areas of Meerut: MD thesis. Meerut: Chaudhary Charan Singh University, 2000

[15]. Anand T, Rahi M, Sharma P, Ingle GK. Issues in prevention of iron deficiency anemia in India. Nutrition. 2014;30(7):764-70.

[16]. Pritwani R, Mathur P. Strategies to Combat Micronutrient Deficiencies: A Review. International Journal of Health Sciences and Research (IJHSR). 2015; 5 (2): 362-73.

[17]. The Adolescent Girls Anaemia Control Programme. New Delhi: UNICEF; 2013. p. 27.

[18]. Mid-Day Meal Scheme: Ministry of Human Resources Development; [Internet] 2013 [Cited 2015 Nov 11]. Available from: http://mdm.nic.in. 